\title{
Effects of Organizational Culture on Organizational Innovation in Small Businesses
}

\author{
M. Apsalone
}

\begin{abstract}
Small businesses play a vital role in smal economies. According to Eurostat, $\mathbf{9 9 . 8 \%}$ of businesses in Latvia are small and medium-sized enterprises (SMEs), creating 79\% of jobs and $70 \%$ of gross added value [1]. Thus, their ability to create value and to sustain competitive advantage through innovation is essential for economic development and growth. Yet many small businesses might face challenges of limited capacity, personnel and insufficient resources for long-term investments in research and development. And, besides the lack of resources, such businesses might not see the benefits of innovation. Implementation of organizational innovation could provide them a way to improve competitiveness and also become a stepping stone to foster other types of innovation.
\end{abstract}

The purpose of this study is to analyze the effects of organizational culture (OC) on organizational innovation in SMEs via an empirical study of businesses from various industries.

The study assesses four dimensions of the OC adopted from Denison and Spreitzer (1991) - Team, Development, Result-orientation and Consistency [2]. And it evaluates the impact of the OC on product, process, marketing and organizational innovation performance in selected companies.

The study confirms that $\mathrm{OC}$ and innovation indicators are closely related. Stronger and more developed $\mathrm{OC}$ in any of the four aforementioned dimensions leads to better innovation performance. This relation is particularly strong for organizational innovation, thus the impact is further analyzed using a regression model. This study finds Development-orientation and Consistency as the most significant factors, explaining $44.6 \%$ of the total variation in the organizational innovation performance. This study contributes to research on small and medium-sized business innovation.

Index Terms - Organizational culture, socio-cultural factors, innovation, organizational innovation, small and medium-sized enterprises.

\section{INTRODUCTION}

Small businesses play an important role in small European economies. According to Eurostat, $99.8 \%$ of businesses in Latvia are small and medium-sized businesses (SMEs), creating $79 \%$ of jobs and $70 \%$ of gross added value [1]. Thus, their ability to create value and sustain competitive advantage through innovation is essential for economic development and growth.

Successful introduction of innovations would allow SMEs to differentiate themselves and find attractive niches with

Manuscript received October 18, 2017; revised January 8, 2018. This work was supported in part by Eigits Dāvis Timermanis scholarship and the Fund of the University of Latvia.

M. Apsalone is with the University of Latvia, Faculty of Business, Management and Economics, Riga, Latvia (phone: +371 27723905 e-mail: madara.apsalone@gmail.com) loyal customers, thus standing out from competition [3]. Yet, the share of European enterprises that are innovative is much lower amongst SMEs - Eurostat reported $48 \%$ of SMEs being innovative in comparison to $78.1 \%$ of large enterprises [1]. Innovation process is complex and uncertain [4] - it can involve significant risk and demand substantial resources. Smaller enterprises might not be able to allocate investments required for such long-term, large-scale innovation projects [5]. And, while larger businesses may develop new ideas along already secured revenue streams, smaller businesses might not have such an opportunity to mitigate their risk SMEs might also face lack of qualified personnel to effectively implement and manage the change. Considering these aspects, SMEs might incur relatively higher costs and might see less benefit to innovate in comparison to large companies.

On the other hand, SMEs may have leaner and more flexible structures and exhibit more entrepreneurial approach [6]. These factors could give them certain advantages, particularly for implementation of non-technological process changes such as new business practices in workplace organization or company's external relations - also referred to as organizational innovations. While the general understanding of innovation is often associated with research and development and creation of new products [7], this study argues that SMEs could greatly benefit, it they could find ways to use their internal factors - structures, work practices and attitudes - towards starting and developing organizational innovations. Successful implementation of organizational innovation could further provide SMEs way to improve competitiveness and foster other types of innovation.

Socio-cultural factors - shared values, norms, attitudes and established ways of working in an organization have been previously highlighted as a crucial aspects for innovation. Studies have demonstrated that long-term thinking, risk-taking abilities and individual responsibility increases innovation capacity [8], [9]. Cultural factors have been linked to attitudes towards independence, risk and the distribution of power [10]-[12]. OC affects productivity through decision-making processes and by enhancing ability to adjust to changes [13]. Cultural values determine tightness and effectiveness of leadership [14]. They also impact effectiveness and productivity [15]. Thus, OC can serve as a source of superior performance and sustained competitive advantage [16]. By fostering such an OC that would promote innovation, one could ensure successful innovation performance in SMEs [17]-[19].

This study examines the effects of OC on innovation in SMEs. In particular, it seeks to explore the relationship between the OC and organizational innovation. This study 
contributes to research on small and medium-sized business innovation.

\section{LITERATURE REVIEW}

\section{A. Defining $O C$}

Culture is a complex phenomenon, which can be defined in different levels and ways. Generally, the measurable culture can be seen as the "collective programming of the mind which distinguishes the members of one category of people from another." [20, page 21]. Culture is learned and group-specific; it stands between of the universal and inherited human nature and individual personalities [21]. Each culture consists of several levels, as individuals can belong to different social groups. This study focuses on the organizational level of culture.

OC can be defined as "a pattern of shared basic assumptions that was learned by a group as it solved its problems of external adaptation and internal integration, that has worked well enough to be considered valid and, therefore, to be taught to new members as the correct way to perceive, think, and feel in relation to those problems" [22, page 17]. Thus OC reflects the way, in which one group of people solves problems and makes choices - it includes group's accumulated learnings, which are further passed on to new members [23].

According to Schein, OC can be analyzed at several levels the surface level consists of tangible artefacts, visible organizational structures and behaviors, the middle level consists of organization's stated values, shared visions and rules of behavior, the lower level is made of shared, embedded assumptions, usually unconscious behaviors [22]. This study focuses on the middle level - espoused beliefs and values. Artefacts can be easy to observe, however do not provide substantial depth in underlying motivations and reasons of the visible aspects. And basic assumptions are hard to recognize from within, thus hard to assess using quantitative study.

Each OC is different and in a way unique. In order to study the impact of OC towards innovation via quantitative means, cultural factors were structured along four dimensions, adopted from Denison and Spreitzer competing values framework, originally developed to measure efficiency [2]. The framework consists of two axis - centralization vs decentralization, as well as competition vs system maintenance. Thus the model suggests four different forms of OC - human relations model (the team), open systems model (the adhocracy), rational goal model (the firm) and internal process model (the hierarchy). In the last dimension the primary interest of this study was the systemic perspective, stability and continuity rather than simply hierarchy, thus it was adopted to consistency.

\section{B. Defining Innovation}

This study follows the Schumpeterian perspective, originally listing five forms of innovation - new products, new production methods, new markets, new supply sources and new forms of organization [24]. Following Schumpeter's division, some innovations are technical (new products and new production methods), while others - non technical. Schumpeter also distinguished between radical innovations as completely new developments and incremental innovations as nonstop process developments. The Schumpeterian perspective is more inclined towards radical innovations and globally new changes. Small businesses, on the other hand, are more likely to implement incremental innovations new to the company.

According to Drucker (1985), an invention becomes a resource, when an organization finds and application for it [25]. Drucker also proposed seven sources of opportunities, where most of the innovative ideas originate: unexpected successes and failures, process incongruities, process needs, changes in industry and market structures, industry and market changes, changes in demographics, changes in perception, and new knowledge.

And Hamel emphasized, that innovation occurs from diverse worldviews. According to his theories, innovation was prerequisite for growth; an enterprise cannot significantly increase profits without new goods and services, and a radical innovation must meet at least one of the preconditions - the need to change consumer perceptions, the need to change the competitive landscape or the need to change the whole industry [26].

A comprehensive overview of innovation framework is provided in the Eurostat's and the Organization's for Economic Co-operation and Development (OECD) Oslo manual, which describes the four main types of innovation: product, process, marketing and organizational innovations. Product innovations include introduction of a new or significantly improved product. Process innovation includes new or significantly improved production or delivery method. Marketing innovations include new marketing methods, significant design or packaging changes, as well as product placement, promotion or pricing. Organizational innovations include new organizational methods in the company's business practices, workplace organization or external relations [27].

Organizational innovations can be defined as teamwork, job enrichment, decentralization and continuous improvement in context of lean production as a driving force for competitiveness in manufacturing companies [28]. They include use of new managerial and working concepts and practices [29]. Organizational innovations can be further categorized as structural or procedural, and inter-organizational, which take place beyond company's boundaries, and intra-organizational, which takes place within company [7].

Organizational innovations can be both - supporting factors for product and process innovations, and aspects improving enterprise performance as such - for instance, changes in organizational methods can improve operational efficiency and quality, thus increasing demand or reducing costs [27].

\section{Methodology}

A structured, closed-ended questionnaire was designed to explore the impact of OC on innovation in Latvian SMEs. The first part of the questionnaire consisted of statements about 
the OC. Team dimension was constructed, considering 1) to what extent employees viewed themselves as partners in setting strategic direction of the company, 2) employees were not afraid to express their opinions, 3) newcomers received help and 4) company conducted business in a transparent way. Transparency was included, as it was considered an important aspect in the original value framework of Denison and Spreitzer [2]. Development dimension was constructed, considering, to what extent 1) company rewarded employees for creativity and innovation, 2) company created and sustained cross-functional expert groups, 3) company was critically reflecting on its assumptions and 4) the company was creative in its work. Result orientation dimension was constructed, considering, to what extent 1) tasks were solved in the most efficient way, 2) the company had a clear vision and understanding on strategic direction, 3) all employees were committed towards the shared goals and 4) there was a system to follow-up task execution. Consistency was constructed, considering, to what extent 1) general meetings were planned in advance and the schedules were respected, 2) rewards and incentives were administrated by objective criteria, 3) capital expenditures were planned timely and 4) plans were formal and written. OC statements regarding team and result orientation were operationalized from Griese [30] and Zortea-Johnston [31], other questions were self-operationalized. OC statements were rated using a seven-point Likert scale from 1, "strongly disagree"' to 7 "strongly agree".

The second part of the questionnaire consisted of statements about product, process, marketing and organizational innovation. These statements were developed, based on definitions provided for each innovation type in the Oslo Manual [27]. Respondents were asked to compare innovation performance in their company compared to innovation performance in competing companies using a seven-point Likert scale from 1, "strongly disagree" to 7 "strongly agree".

The third part of the questionnaire consisted of background questions, helping to understand the profile of the company. This part included questions about industry and how long the company had been working in it, the number of employees and the turnover dynamics. It was also used to collect information regarding the lifecycle stage of the company from the establishment, towards initial development, intensive development, stability and decline.

Due to the nature of the study, definition of SMEs as in the United States of America was applied, including businesses with no more than 500 employees. Such an approach allowed to cover a sufficient base of enterprises in the analysis without including large corporations and industry leaders, which may exhibit significantly different cultural traits and influences on innovation processes.

The questionnaire was distributed amongst senior managers of SMEs in Latvia, and 53 responses were received. The companies were selected, using a snowball sampling method, and represented various industries, primarily services.

\section{RESEARCH RESULTS AND DISCUSSION}

According to the survey results, enterprises had been working on average from 5 to 20 years in their respective industries, and they employed, on average, from 50 to 100 employees. Most of the respondents informed that the number of employees in their enterprise had slightly increased over the last years. The average turnover was from 1 to 20 million EUR, and, according to respondents, the turnover had slightly decreased over the last years.

Analyzing the OC along the aforementioned dimensions, it is visible that Latvian SMEs are more Team, Consistency and Development oriented, while thy do not have a very distinct Result-orientation (Fig. 1).

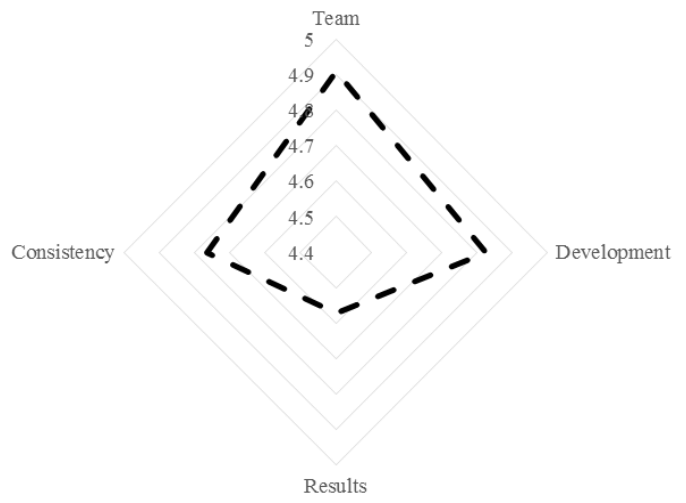

Fig. 1. Organizational culture.

The Team orientation was particularly strong for small companies with less than 50 employees; at the same time such companies had the weakest result orientation. Generally, all OC dimensions were the strongest earlier in company's lifecycle.

Comparing results of the innovation performance, product innovations were the most common amongst the respondents (rather on average 5.19 of 7), while process innovations were the least common (rated on average slightly below 4 of 7). (Fig. 2)

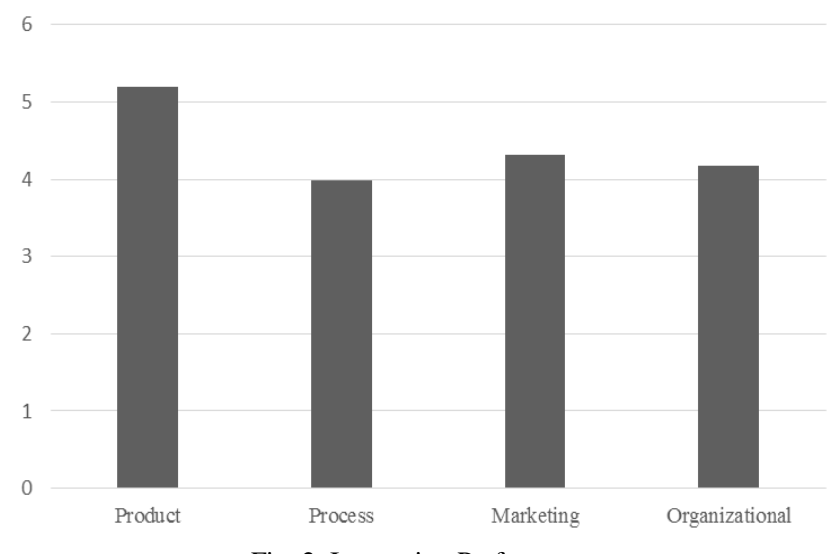

Fig. 2. Innovation Performance.

The relatively lower process innovation performance could be explained due to larger percentage of service companies in the sample, for which process innovation, especially new or significantly improved production methods might have been comparably less relevant.

New enterprises reported product innovations more frequently, while other types of innovation were the more frequent during the intensive development stage. Performance of marketing and organizational innovations was the highest during stability and decline. Thus it is possible to conclude 
that these forms are the most relevant later in development stage.

Correlation analysis was used to explore the relationships between $\mathrm{OC}$ and innovation performance. Making an assumption that the Likert scale indicating just the values of end-poles is suitable for parametric methods, the Pearson correlation coefficient was used. This coefficient takes values in a range from +1 to -1 ; a value of 0 indicates that there is no association between the two variables. A value greater than 0 indicates a positive association, and a value less than 0 indicates a negative association. Statistically significant correlations are displayed in the Table I.

TABLE I: OC AND INNOVATION PERFORMANCE

\begin{tabular}{lllll}
\hline \hline Culture & Product & Process & Marketing & Organizational \\
\hline Team & $.436^{* *}$ & $.425^{* *}$ & $.303^{*}$ & $.538^{* *}$ \\
Development & $.412^{* *}$ & $.335^{*}$ & & $.601^{* *}$ \\
Results & & $.335^{*}$ & $.338^{*}$ & $.520^{* *}$ \\
Consistency & $.401^{* *}$ & $.355^{*}$ & $.327^{*}$ & $.484^{* *}$ \\
\hline \hline
\end{tabular}

**statistically significant at the 0.01 level

*statistically significant at the 0.05 level

Thus we can conclude that a moderate, positive, statistically significant link exists between all OC variables and the indicators of innovation performance. The link is particularly strong between OC and organizational innovation.

The impact of OC on organizational innovation is further analyzed using a liner regression model. The Four dimensions of OC - Team, Development, Results and Consistency were considered as the input values in this model. And organizational innovation performance was considered as the dependent variable. A stepwise method with input variable selection criteria probability-of-F-to-enter $<=.050$, probability-of-F-to-remove $>=.100$ was used, to consider just the significant factors in the model. Following this approach, Development and Consistency were included in the models explaining organizational innovations. Summary of regression models is provided in Table II.

TABLE II: SUMMARY OF REGRESSION MODELS

\begin{tabular}{llllll}
\hline \hline Model & $R$ & $\begin{array}{c}R \\
\text { Square }\end{array}$ & $\begin{array}{l}\text { Adjusted } \\
R \text { Square }\end{array}$ & $\begin{array}{l}\text { Std. Error of } \\
\text { the Estimate }\end{array}$ & $\begin{array}{l}\text { Durbin- } \\
\text { Watson }\end{array}$ \\
\hline $1^{*}$ & $.624^{\mathrm{a}}$ & .390 & .377 & .89752 & \\
$2^{* *}$ & $.668^{\mathrm{b}}$ & .446 & .421 & .86458 & 2.250 \\
\hline \hline
\end{tabular}

*Input values: Development

** Input values: Development and Consistency

From the given models, model with the highest adjusted $\mathrm{R}^{2}$ was selected, thus the model including input values of Development and Consistency.

Considering the second model, it is possible to conclude that $44.6 \%$ of the total variation in the organizational innovation performance can be explained by inputs of OC Development and Consistency. The ANOVA analysis confirms that the regression model statistically significantly predicts the outcome variable. And the Durbin-Watson statistic is 2.25 , which is between 1.5 and 2.5 and therefore the data can be considered as not auto correlated.

Coefficients of the independent variables - Development and Consistency are provided in the Table II. Coefficients of both variables are statistically significant.

TABLE III: COEFFICIENTS OF INPUT VALUES

\begin{tabular}{lrrrcc}
\hline \hline & B & Std. Error & Beta (stand.) & $t$ & sig. \\
\hline constant & 1.270 & .515 & & 2.465 & .018 \\
Development & .425 & .102 & .511 & 4.152 & .000 \\
Consistency & .200 & .093 & .263 & 2.138 & .038 \\
\hline \hline
\end{tabular}

\section{CONCLUSIONS, LiMITATIONS AND FUTURE RESEARCH}

This study considered OC and innovation in Latvian SMEs. The previous literature review confirms that $\mathrm{OC}$ affects innovation performance, for instance, through leadership, decision-making and international cooperation. OC can also $n$ help to attract certain type of talent, thus affecting organizational competitiveness and performance also though human resource developments.

The results show that SMEs in Latvia have stronger Team-orientation and weaker Result-orientation. Team-orientation is particularly significant for small enterprises with no more than 50 employees. And all OC factors are the highest in during intensive development and stability of enterprise life-cycle.

Product innovations were the most common - process innovations the least common amongst the surveyed Latvian enterprises. Perhaps unsurprisingly, enterprises were the most innovative during early development stages, when they introduced the highest level of new products. For other innovation types the performance was the highest during the intensive development stage.

This study has examined the effects of OC on innovation performance. It confirms that moderate, statistically significant relation exists between the selected OC dimensions and all forms of innovation. The positive link means that more developed culture in the considered dimensions is linked to a higher innovation performance. This link was particularly strong between the OC and organizational innovation performance.

Applying a linear regression model to explain organizational innovation using OC input factors, this study finds Development-orientation and Consistency as the most significant factors, explaining $44.6 \%$ of the total variation in the organizational innovation performance.

In terms of practical implications, this study has highlighted that SMEs need to be mindful of their own cultures - values, norms and behaviors - and try to shape their cultures in such a way that the OC can positively contribute to their innovation performance.

Several limitations exist to this study. Firstly, the sampling method and the rather small sample size of diverse enterprises do not give an opportunity to assess impact of demographic indicators - for instance, whether OC impacts innovation differently in micro-enterprises than in mini enterprises. While this study did not find a statistically significant difference between small and medium-sized enterprises, micro enterprises could have different results. This could be further explored through a larger study that used random sampling techniques.

Secondly, some forms of innovation might be more common and beneficial for companies from certain industries 
- for instance, certain technological changes and process improvements could be more relevant to manufacturing than for trade and services. Questionnaire design did not include assessment of whether certain innovation would be been necessary, it just compared companies to each other. Moreover the questionnaire focused on innovations implemented during a three-year timeframe - while this allows to capture recent developments in product innovations, it may overlook early adaptors and favor later adaptors, when assessing organizational innovation. A differentiated scale could be developed in further research to assess organizational innovations, adressing this issue.

\section{REFERENCES}

[1] Eurostat - Data, June 6, 2017

[2] D. R. Denison and G. M. Spreitzer, "Organizational culture and organizational development: A competing values approach," Research in Organizational Change and Development, vol. 5, no. 1, pp. 1-21, May 1991.

[3] M. E. Porter, Competitive Strategy: Techniques for Analyzing Industries and Competitors, Free Press, New York, 1980.

[4] S. J. Kline and N. Rosenberg, "An overview of innovation," The Positive Sum Strategy: Harnessing Technology for Economic Growth, Washington, DC: The National Academies Press, p. 640, 1986.

[5] Z. J. Acs and D. B. Audretsch, "Innovation in large and small firms: An empirical analysis," American Economic Review, vol. 78, no. 4, pp. 678-690, 1988

[6] B. Nooteboom, "Innovation and diffusion in small firms: theory and evidence," Small Business Economics, vol. 6, no. 5, pp. 327-347, 1994.

[7] H. Armbruster, A. Bikfalvi, S. Kinkel, and G. Lay, "Organizational innovation: The challenge of measuring non-technical innovation in large-scale surveys," Technovation, vol. 28, no. 10, pp. 644-657, 2008

[8] W. R. King, "A research agenda for the relationships between culture and knowledge management," Knowledge and Process Management, vol. 14 , no. 3 , pp. 226-236, Jul. 2007.

[9] A. Turró, D. Urbano, and M. Peris-Ortiz, "Culture and Innovation: the Moderating Effect of Cultural Values on Corporate Entrepreneurship,' Technological Forecasting and Social Change, vol. 88, pp. 360-369, 2014.

[10] S. Shane, "Cultural values and the championing process," Entrepreneurship: Theory \& Practice, vol. 18, no. 4, pp. 25-41, Jun. 1994.

[11] J. Tan, "Culture, nation, and entrepreneurial strategic orientations: implications for an emerging economy," Entrepreneurship: Theory \& Practice, vol. 26, no. 4, pp. 95-111, 2002.

[12] C. Alvarez and D. Urbano, "Cultural-cognitive dimension and entrepreneurial activity: A cross-country study," Revista de estudios sociales, vol. 44, pp. 146-57, Dec. 2012.

[13] C. D. Throsby, Economics and Culture, Cambridge, Cambridge UP., 2001.

[14] M. Aktas, M. J. Gelfand, and P. J. Hanges, "Cultural tightness-looseness and perceptions of effective leadership," Journal of Cross-Cultural Psychology, vol. 47, no. 2, pp. 294-309, Sept. 2015.

[15] R. J. House and M. Javidan, Leadership and Cultures around the World: Findings from GLOBE, New York, 2002.

[16] J. B. Barney, "Strategic Factor Markets: Expectations, Luck, and Business Strategy," Management Science, vol. 32, no. 10, pp. 1231-1241, 1986.

[17] A. Ledwith, "Management of new product development in small electronics firms," Journal of European Industrial Training, vol. 24 nos. 2/4, pp. 137-148, 2000.
[18] S. Laforet and J. Tann, "Innovative characteristics of small manufacturing firms," Journal of Small and Enterprise Development, vol. 13 , no. 3, pp. 363-390, 2006.

[19] A. Pullen, P. de Weerd-Nederhof, A. Groen, M. Song, and O. Fisscher, "Successful patterns of internal SME characteristics leading to high overall innovation performance," Creativity and Innovation Management, vol. 18, no. 3, pp. 209-223, 2009.

[20] G. Hofstede, Culture's consequences: International Differences in Work-Related Values, vol. 5, Sage, 1984.

[21] G. H. Hofstede and G. J. Hofstede, Cultures and Organizations: Software of the Mind, New York: McGraw-Hill, 2005.

[22] E. H. Schein, Organizational Culture and Leadership, $3^{\text {rd }}$ ed., Jossey Bass, 1985

[23] M. R. Louis, "Surprise and sense making: What newcomers experience in entering unfamiliar organizational settings," Administrative Science Quarterly, pp. 226-251, 1980.

[24] J. Schumpeter, The Theory of Economic Development, Harvard University Press, Cambridge, Massachusetts, 1934.

[25] P. F. Drucker, Innovation and Entrepreneurship, London, 1985.

[26] G. Hamel, Leading the Revolution, Harvard Business School Press, Boston, vol. 364, 2000.

[27] OECD-Eurostat - Oslo manual. (2005) http://www.oecd-ilibrary.org/science-and-technology/oslo-manual_97 89264013100-en

[28] J. Womack and D. Jones, The Machine That Changed the World: The Story of Lean Production, Harper Perennial, New York. 1990.

[29] F. Damanpour, "The adoption of technological, administrative and ancillary innovations: impact of organizational factors," Journal of Management, vol. 13, no. 4, pp. 675-688, 1987

[30] I. Griese, D. Pick, and M. Kleinaltenkamp, "Antecedents of knowledge generation competence and its impact on innovativeness," Journal of Business \& Industrial Marketing, vol. 27, iss. 6, pp. 468-485, 2012.

[31] E. Zortea-Johnston, J. Darroch, and S. Matear, "Business orientations and innovation in small and medium sized enterprises," International Entrepreneurship and Management Journal, vol. 8, no. 2, pp. 145-164, 2011.

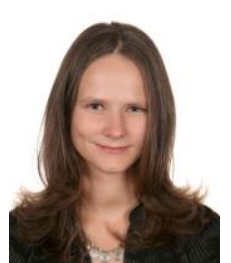

Madara Apsalone is a Ph.D. student of management science (Business Administration) at the University of Latvia, Faculty of Business, Management and Economics in Riga, Latvia. She received MS in international business and economics from the University of Latvia Riga, Latvia in 2011 and MBA in global management with distinction from Thunderbird School of Global Management, Phoenix, Arizona, USA in 2010. She is also a PMI certified Project Management Professional (PMP).

Her expertise is global leadership and strategy; she has an extensive experience working with European Union policy and International Affairs for the Latvian government, global business at the Investment and Development Agency of Latvia and international education at the Erasmus Student Network - the largest international student association in Europe. Since fall 2016 she works for Philip Morris as the Corporate Affairs Manager of Latvia.

She is a researcher in project "Involvement of the society in social innovation for providing sustainable development of Latvia," conducted within the National Research Program "Economic Transformation, Smart Growth, Governance and Legal Framework for the State and Society for Sustainable Development - a New Approach to the Creation of a Sustainable Learning Community (EKOSOC-LV)". Her research interests include socio-cultural factors, organizational competitiveness, innovation and business ethics. 